\title{
EVALUATION AND CHARACTERIZATION OF BIOACTIVE COMPOUND OF HAMELIA PATENS PLANT WITH THE GC-MS SPECTROSCOPY
}

\author{
JAFRA BANO*, SWAPNA SANTRA, EKTA MENGHANI
}

Department of Biotechnology, JECRC University, Jaipur - 303 905, Rajasthan, India. Email: jafrabano@gmail.com

Received: 26 May 2018, Revised and Accepted: 09 July 2018

ABSTRACT

Objective: The aim of this study is to evaluate the bioactive compound present in the leaves, root, flower, and stem by gas chromatography (GC) analysis. Novel drugs are isolated from plants against human diseases.

Methods: The plant parts (leaves, stem, flower, and root) were collected, washed, shade dried, and powdered, and the methanol extracts of all plant parts were prepared by Soxhlet reflux method. The methanolic extracts were analyzed for the identification of phytochemical compounds present in the Hamelia patens plant parts using GC-mass spectrometry (MS) matched by the National Institute of Standards And Technology-11 library and Willey 8 library.

Results: The bioactive fraction on GC-MS analysis revealed a chromatogram showing highest peaks. Methanol extracts of $H$. patens leaf are found to possess a wide range of saturated and unsaturated aliphatic hydrocarbons and their isomers such as 2,3-dihydro-3,5-dihydroxy-6-methyl4H-pyran (1.77\%), 1,3-propanediol, 2-ethyl-2-(hydroxymethyl) (3.06\%), mome inositol (18.22\%), pentadecanoic acid (1.66\%), and squalene (11.47\%). GC-MS analysis revealed chromatogram, showing that the highest peaks of $H$. patens stem are methyl salicylate (3.41\%), 2-amino-9-(3,4dihydroxy-5- hydroxymethyl) (9.53\%), mome inositol (63.73\%), and squalene $(1.07 \%)$.

Conclusion: Isolation of such bioactives and their use as therapeutic target is the prime motto of our research to isolate novel bioactive that can used as potential therapeutic agents.

Keywords: Gas chromatography, Methanol extract, Bioactive, Therapeutic agent, National Institute of Standards And Technology, Willey.

(C) 2018 The Authors. Published by Innovare Academic Sciences Pvt Ltd. This is an open access article under the CC BY license (http://creativecommons. org/licenses/by/4. 0/) DOI: http://dx.doi.org/10.22159/ajpcr.2018.v11i11.27557

\section{INTRODUCTION}

Plants have been a key source of quality medicines for thousands of years. Knowledge of the secondary metabolites and volatile matter released by plants, play important role in drug discovery [1]. When gas chromatography is coupled to mass spectrometry (GC-MS), additional information takes place about molecular mass, elemental composition (when high-resolution MS is used), functional groups, and in certain cases, molecular geometry and spatial isomerism of each separated complex [2]. Natural sources of herbal medicines are more protective, safe, biodegradable, fewer side effect than artificial and synthetic remedies because the phytochemicals in the plant extract target the biochemical pathway. The unknown organic compounds in a complex mixture can be resolute by matching the spectrum of the test sample with reference spectra. $H$. patens Jacq. is generally known as scarlet bush or firebush. It is a perennial shrub or small tree. This plant is used in folk medicine against a range of ailments. The plant possesses analgesic, antiseptic, anti-inflammatory, febrifuge, and refrigerant properties. Firebush is used in herbal medicine to treat athlete's foot, skin lesions and rash, insect bites, nervous shock, inflammation, rheumatism, headache, asthma, and dysentery [3]. GC is a predictable technique to discover out how many components and in what proportion they are present in a composite mixture of volatile compounds.

Many plants contain many pure drugs those are very useful for the dangerous diseases [4]. Synthetic medicines for some diseases are so expensive unaffordable by poor people and not available for everywhere and approachable the normal people. If these active elements are finding in the plants, herbal medicines can sometimes grow and produce easily by the people at a lower cost [5].
Ayurveda strains the use of plant-based medicines and treatments. Chinese medicine is more acceptable than ayurvedic medicine. This is due to the level after Chinese people migrating to additional countries they still follow their own culture. And also, the Chinese people wherever in the world are dynamically contributing in export and import of their medical system. GC-MS is a hyphenated system which is a very compatible technique and the most frequently used technique for the identification and quantification idea. The unknown organic compounds in a complex mixture can be determined by analysis and also by matching with the spectra with reference spectra [6]. Many medicinal plants are an affluent resource of secondary metabolites such as alkaloids, phenol, cardiac glycosides, flavonoids, and tannins; furthermore, terpenoids are determined by GC and also by mass spectrum [7]. Natural medicines are secured than synthetic medicines since the phytochemicals in the plant extract purpose the biochemical pathway [8].

\section{METHODS}

Preparation of plant part extracts for analysis

The sample of H. patens plant was collected from Sitapura, Jaipur, and was identified from the botanist of Rajasthan University, the RUBL no. is 206311. Plant Soxhlet extraction, the oldest and conventional method of extraction of bioactive substances from natural sources, was employed for extract preparation [9]. $100 \mathrm{~g}$ of air leaf, stem, flower, and root powder is extracted with the hot extraction method in Soxhlet [7]. The solution of extracted was filtered through the Wattman filter paper. The plant part extracts were evaporated to the elimination of excessive solvents from the powder. Pure compounds are identified with GC-MS analysis, these extracts were stored in dry place [10]. 


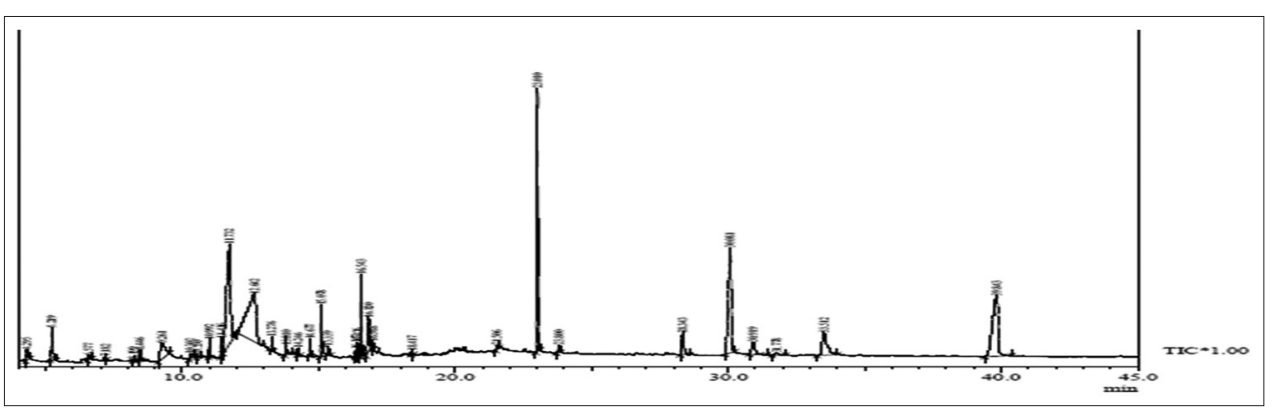

Fig. 1: Graphical presentation of bioactive compounds from the methanol extract of Hamelia patens leaf extract

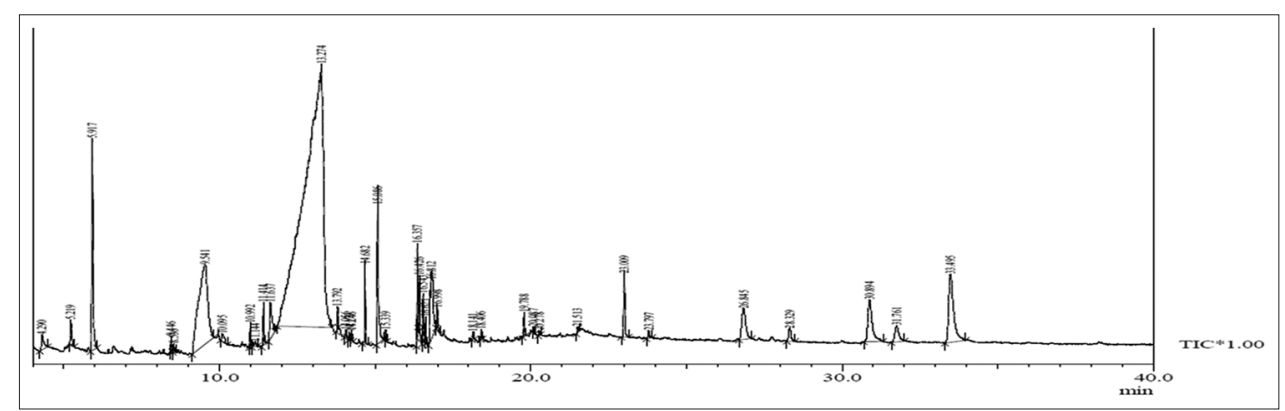

Fig. 2: Graphical presentation of bioactive compounds from the methanol extract of Hamelia patens stems extract

Table 1: Phytocomponents identified in the methanol leaf extracts of $H$. patens

\begin{tabular}{|c|c|c|c|c|}
\hline S. No. & RT & Area & Area \% & Compound name \\
\hline 1 & 4.295 & 525828 & 0.78 & 1,3,5-triazine-2,4,6-triamine \\
\hline 2 & 5.19 & 1196682 & 1.77 & 2,3-dihydro-3,5-dihydroxy-6-methyl-411-pyran \\
\hline 3 & 9.261 & 2065405 & 3.06 & 1,3-propanediol, 2-ethyl-2-(hydroxymethyl) \\
\hline 4 & 10.302 & 351926 & 0.52 & Carbazic acid, 3-pentyledene-, methyl ester \\
\hline 5 & 10.992 & 327296 & 0.48 & 9-Eicosene, (E)- \\
\hline 6 & 11.416 & 400995 & 0.59 & 1,2,4-trimethoxy-5-[(1e)-1-propynyle] benzene \\
\hline 7 & 11.732 & 11333072 & 16.78 & 1,3,4,5-tetramethoxy-cyclohexanecarboxylic acid \\
\hline 8 & 12.642 & 12306114 & 18.22 & Mome inositol \\
\hline 9 & 13.210 & 675077 & 1.00 & 26 10-trincethyl, 14-ethylene-14-pentadecne \\
\hline 10 & 14.677 & 287849 & 0.43 & hexadecanoic acid, Methyl ester \\
\hline 11 & 15.072 & 1119277 & 1.66 & Pentadecanoic acid \\
\hline 12 & 16.543 & 1684865 & 2.49 & $\begin{array}{l}\text { 2-11-hexadecane-1-ol- } 3711 \text { 15-tetramethyl-2- } \\
\text { hexadecen-1-ol }\end{array}$ \\
\hline 13 & 16.230 & 1766176 & 2.62 & (ZZ)-69-Cis-3:4-Epdxy-Nonadecadelene \\
\hline 14 & 12.417 & 92164 & 0.14 & Tetradecanedioic acid: Dal: Ethyl ester \\
\hline 15 & 21.506 & 133399 & 0.20 & Hexadecane, 2,6,10A 4-Tetraivie \\
\hline 16 & 23.010 & 7748216 & 11.47 & Squalene \\
\hline 17 & 23.200 & 280165 & 0.41 & 2-methyloctacosane \\
\hline 18 & 28.343 & 1443990 & 2.14 & dl-alpha-tocopherol acetate \\
\hline 19 & 30.081 & 7995960 & 11.84 & 41-1-Indolo[2,3-A] Pyrano[3,4-G]-quinolizine (DX) \\
\hline 20 & 30.919 & 1225988 & 1.82 & Ergost-5-En-3-Cil, (3.Beta, 24R)- \\
\hline 21 & 33.512 & 3166119 & 4.69 & Gamma-sitosterol \\
\hline 22 & 39.843 & 9456458 & 14.00 & Mitrajavine \\
\hline
\end{tabular}

RT: Retention time, H. patens: Hamelia patens

\section{Preparation of extracts for GC-MS analysis}

The dried extract of $H$. patens was dissolved in absolute methanol $(1 \mathrm{mg} / \mathrm{ml}) .10 \mathrm{ml}$ of this sample was then injected for GC-MS analysis.

\section{Interpretation of mass spectrum analysis}

The methanol extracts of $H$. patens were used for the identification of various bioactive compounds present. Samples were prepared accordingly for analysis; mixture was filtered properly to get crystalfree sample. The homogeneous solution was collected in Eppendorf after testing it with microinjection. Finally, samples were handed over to the head of respective instruments at JNU, where samples were loaded in injector and processed. Chromatogram with compounds detected in solvent was known.
The samples of plant parts were analyzed in GCMS-QP2010 plus commencing the Delhi University, India. A sample of methanol extract was injected at temperature $260^{\circ} \mathrm{C}$ with the split ratio of $10: 0$, and the temperature in initial time is $100^{\circ} \mathrm{C}$ and it reached at $250^{\circ} \mathrm{C}$ for the 5 minutes and $280^{\circ} \mathrm{C}$ temperature was hold for $69.98 \mathrm{~min}$. The column flow is $1.21 \mathrm{~mL} / \mathrm{min}$ and total flow is $16.3 \mathrm{ml} / \mathrm{min}$. The identification of secondary metabolite bioactive compounds with the matching of mass spectra of standards WILLEY 8 library and National Institute of Standards and Technology (NIST) 11 library. The name, structure, and molecular weight (MV) of compounds were ascertained with the standards.

Chromatograms depict the number of peaks detected in solvent. Peaks confirm the presence of different compounds with a respective 
Table 2: Phytocomponents identified in the methanol stem extracts of $H$. patens

\begin{tabular}{lllll}
\hline S. No. & RT & Area & Area $\%$ & Name \\
\hline 1 & 4.290 & 402906 & 0.44 & 1,3,5-triazine-2,4,6-triamine \\
2 & 5.219 & 421718 & 0.46 & 4H-Pyraa-4-one, 2,3-dthydro-3,5-clitc.idroKy-6-methyl \\
3 & 5.917 & 3107625 & 3.41 & Methyl salicylate \\
4 & 9.541 & 2697818 & 9.53 & 2-amino-9-(3,4-dihydroxy-5-hydroxymethyl) \\
5 & 11.637 & 966400 & 1.06 & 1,3,4,5-tetrahydroxy-cyclohexanecarboxyl \\
6 & 11274 & 58137529 & 63.73 & Moms inositol \\
7 & 14.682 & 70.2047 & 0.78 & Hexadecanoic acid methyl ester \\
8 & 15.086 & 2095725 & 2.30 & Decanoic acid \\
9 & 16357 & 706727 & 0.77 & 9 ,12-Octadecadienoic acid \\
10 & 16.426 & 622050 & 0.69 & 9 -1215-Octadecadienoic acid \\
11 & 16.812 & 2331850 & 2.56 & Squalene \\
12 & 21009 & 972863 & 1.07 & Methyl 2-oxooctadecanoate \\
13 & 26.845 & 1443354 & 1.58 & d1-alpha-tocopherol \\
14 & 28.329 & 402651 & 0.44 & Ereast-5-en-3-oL (3.beta) \\
15 & 30.894 & 2107678 & 2.31 & Stigmasterol \\
16 & 31.761 & 752748 & 0.83 & Stigmast-5-En-3-Ol, (3, Beta, 24S) \\
17 & 31495 & 3935130 & 4.31 &
\end{tabular}

RT: Retention time, H. patens: Hamelia patens

Table 3: Major compounds identified by GC MS in H. patens

\begin{tabular}{|c|c|c|c|}
\hline S.NO & Compound name & GC-MS chromatogram & Structure \\
\hline 1 & Mome inositol & 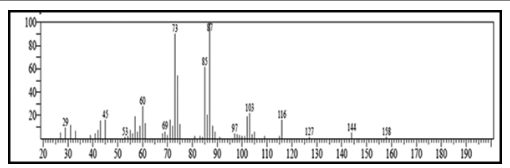 & - \\
\hline 2 & Squalene & 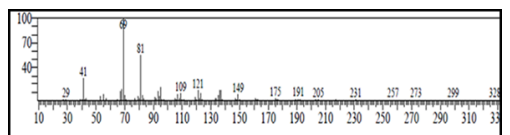 & \\
\hline 3 & Gamma-sitosterol & 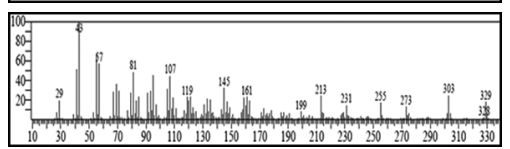 & \\
\hline 4 & Mitrajavine & $\underbrace{}_{10}$ & - \\
\hline 5 & Pentadecanoic acid & 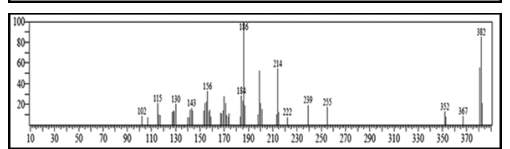 & \\
\hline 6 & 9-Octadecenoic acid & 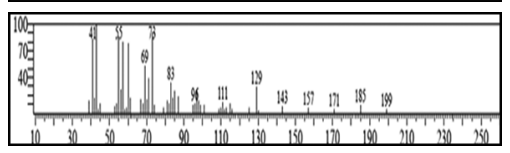 & \\
\hline 7 & Ergost 5 -en-3-ol $(3$, beta) & 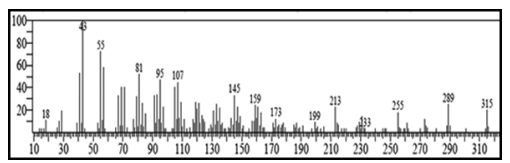 & \\
\hline 8 & Stigmast-7-en-3-ol & 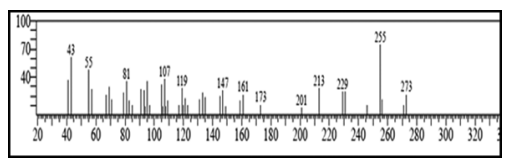 & \\
\hline
\end{tabular}

RT: Retention time, H. patens: Hamelia patens, GC-MS: Gas chromatography-mass spectroscopy

retention time (RT), and the area covered by the peaks is directly proportional to the amount of compound present in the solvent. The peaks were selected and compared with standard, which automatically generated the list of compounds. The identification of compounds was confirmed the mass spectroscopy date with date obtained from the literature. 


\section{RESULTS}

\section{Identification of compounds}

The results pertaining to the GC-MS analysis leads to the identification 131 compound from the GC fractions of the methanol extracts of $H$. patens leaf, stem, flower, and root, respectively. The identification of phytocompounds was based on the MV, molecular formula, RT, and peak area \% (concentration). It is indicating the compound comprises any medicinal property. The GC mass spectrum of the samples was interpreted according to standard database of NIST having 2,00,000 patterns. The various components present in the methanol extracts of H. patens as detected by GC-MS analysis are presented in Tables 1 and 2. Analysis of bioactive compounds with the spectroscopy technique of GC-MS showed the data, which are confirmed, with the library data at further stage. With the knowledge of MV, the compound is easily detected and finds out its elemental position.

\section{H. patens leaf extract}

The bioactive fraction on GC-MS analysis revealed a chromatogram showing highest peaks; accordingly, Fig. 1 represents the total ion chromatogram of methanol of $H$. patens. Methanol extract of $H$. patens leaf is found to possess a wide range of saturated and unsaturated aliphatic hydrocarbons and their isomers such as 2,3-dihydro-3,5-dihydroxy-6methyl-4H-pyran (1.77\%), 1,3-propanediol, 2-ethyl-2- (hydroxymethyl) (3.06\%), 1,3,4,5-tetrahydroxy-cyclohexane carboxyl (16.78\%), mome inositol (18.22\%), pentadecanoic acid (1.66\%), squalene (11.47\%), 4H-Indalo (2,3-A)-pyrano (3,4-G)-quinolizine (11.84\%), and mitrajavine (14.00\%) (Table 1).

\section{H. patens stem extract}

The bioactive fraction on GC-MS analysis revealed a chromatogram showing highest peaks of major compound in crude; accordingly, Fig. 2 represents Methyl salicylate (3.41\%), 2-Amino-9- (3,4-dihdroxy-5hydroxymethyl) (9.53\%), Mome inositol (63.73\%), Pentadecanoic acid (2.30\%), 9-octadecenol (2.56\%), Squalene $(1.07 \%)$, Formosanan16-carboxylic acid - (1.58\%), Ergost-5- en-3-ol, (3,beta) $(2.31 \%)$ and Stigmast-5-en-3-ol (4.31\%) (Table 2).

\section{DISCUSSION}

Evaluation of the methanol extracts of $H$. patens leaves, stem, and root powder showed positive outcomes for the majority of phytochemical constituents. According to the results, identified compounds are medicinally very important and they are helpful for the cure of many infections. The most of the compounds identified in this study belong to saturated and unsaturated aliphatic hydrocarbons, and their isomers are known to have antibacterial and antifungal properties. The activity of compounds was recognized from the Dr. Duke's Phytochemical and Ethnobotanical Databases [11] and is given in Tables 1-3.

\section{CONCLUSION}

The herbal drug consumption is more than the synthetic medicine for the treatment of various types of ailments and diseases. At present, most of the population still relies on plant-based drugs for health care [12]. The maximum qualities of flora found in India throughout the world. Isolation of such bioactive and their use as therapeutic target is the prime motto of our research to isolate novel bioactive that can used as potential therapeutic agents. Several bioactive compounds are isolated from $H$. Patens with the help of GC-Ms technique. Therefore, GC-MS technique is a direct and quick analytical approach for the recognition of terpenoids and steroids, and only few grams of plant material is necessary. The significance of the study is due to the biological action of a number of compounds [13].

Few of the compounds reported by the author were the first report from this plant. Further, isolated compounds and their proper bioactivity screenings are also in process. These identified phytocompounds are presumed to the responsible for eliciting the traditional activity of H. patens.

\section{ACKNOWLEDGMENT}

The authors extend their appreciation to the JECRC University, Jaipur, India, for providing necessary facilities and support for completion of this work.

\section{AUTHORS' CONTRIBUTION}

Jafra Bano and Dr. Ekta menghani contributed to the design and main conceptual ideas of outline. Jafra Bano processed the experimental data, performed the analysis, drafted the manuscript, and designs the figures. Dr. Ekta Menghani and Dr. Swapna santra interpreting the results and worked on the manuscript. All authors discussed the results and final approval of the version to be published.

\section{CONFLICTS OF INTEREST}

The authors declare that there are no conflicts of interest regarding the publication of this article.

\section{REFERENCES}

1. Sathya A, Ramasubramaniaraja R, Brindha P. Pharmacognostical, phytochemical and GC-MS investigation of successive extract of Gymnema sylvestre R. Br. J Pharm Res 2010;3:984-7.

2. Edeoga HO, Okwu DE, Baebie BO. Phytochemical constituents of some Nigerian medicinal plants. Afr J Biotechnol 2005;4:685-8.

3. Hites RA. Gas chromatography and mass spectrometry. Ch. 31. In: Settle B, editor. Handbook of Instrumental Techniques for Analytical Chemistry. NJ, USA: Prentice Hall Publishers; 1997. p. 609-26.

4. Wagner H, Ulrich-Merzenich G. Synergy research: Approaching a new generation of phytopharmaceuticals. Phytomedicine 2009;16:97-110.

5. Hirt HM, Pia BM. Natural Medicine in the Tropics I: Foundation Text. Winnenden: Anamed; 2008. p. 124-56.

6. Elizabeth GE, Aneesh TP, Thomas DG, Anandan R. GC-MS analysis of phytochemical compounds present in the rhizomes of Nervilia aragoana. Asian J Pharm Clin Res 2013;6:68-74

7. Kumar SS, Samydurai P, Ramakrishnan R Nagarajan N. Gas chromatography and mass spectrometry analysis of bioactive constituents of Adiantum capillus-veneris. Int J Pharm Pharm Sci 2014;6:60-3.

8. Balaji K, Kilimozhi D. GC-MS analysis of various extracts of Clerodendrum phlomidis leaf. Int J Pharm Pharm Sci 2013;6:226-32.

9. Naik GH, Priyadarsini KI, Satav JG, Banavalikar MM, Sohoni DP, Biyani MK, et al. Comparative antioxidant activity of individual herbal components used in ayurvedic medicine. Phytochemistry 2003;63:97-104.

10. Sumathi P, Parvathi A. Antimicrobial activity of some traditional medicinal plants. J Med Plant Res 2010;4:316-21.

11. Zaidan MR, Noor Rain A, Badrul AR, Adlin A, Norazah A, Zakiah I, et al. In vitro screening of five local medicinal plants for antibacterial activity using disc diffusion method. Trop Biomed 2005;22:165-70.

12. Duke JA, Beckstrom-Sternberg SM. Phytochemical and Ethnobotanical Databases, Duke's Phytochemical and Ethnobotanical Databases. Available from: http://www.huilesutiles.eu/docs/patchouli.pdf. [Last cited on 2013 Mar 11].

13. Sermakkani M, Thangapandian V. GC-MS analysis of Cassia italic leaf methanol extract, Asian J Pharm Clin Res 2012;5:90-4 